\title{
Diabetes mellitus and the risk of non-vertebral fractures: the Tromso Study
}

\author{
Luai A. Ahmed • Ragnar M. Joakimsen • \\ Gro K. Berntsen • Vinjar Fønnebø • Henrik Schirmer
}

Published online: 4 February 2009

(C) International Osteoporosis Foundation and National Osteoporosis Foundation 2009

Erratum to: Osteoporos Int (2006) 17: 495-500.

DOI 10.1007/s00198-005-0013-x

Owing to a technical error, a number of non-vertebral fractures were not included in the database.

Owing to changes in the informed consents for some of the participants, at the time of repeated analyses, the study cohort changed from 27,159 to 26,905 participants.

A total of 758 men and 1,124 women (not 446 men and 803 women as stated in the publication) suffered at least one non-vertebral fracture during the follow-up period.

Women with type I diabetes had a significantly increased non-vertebral fracture risk [age-adjusted RR 3.7 (95\% CI 1.58.9)], while type II diabetic women and women using insulin no longer had a significantly increased hip fracture risk.

We apologize for any inconvenience caused by this unfortunate error.

The online version of the original article can be found at http://dx.doi. org/10.1007/s00198-005-0013-x

L. A. Ahmed $(\bowtie) \cdot$ G. K. Berntsen $\cdot$ V. Fønnebø $\cdot$ H. Schirmer Institute of Community Medicine, University of Tromsø, 9037 Tromsø, Norway

e-mail: Luai.Awad@ism.uit.no

R. M. Joakimsen

Department of Internal Medicine, University Hospital of Tromsø,

Tromsø, Norway

H. Schirmer

Department of Cardiology, University Hospital of Tromsø,

Tromsø, Norway 